\title{
Future Sleep Medicine: Mobile Health and Big Data
}

\author{
Jiyoung Kim ${ }^{1}$, Jae Wook $\mathrm{Cho}^{2}$ \\ ${ }^{1}$ Department of Neurology, Pusan National University Hospital, Pusan National University College of Medicine, Busan, \\ ${ }^{2}$ Department of Neurology, Pusan National University Yangsan Hospital, Pusan National University College of Medicine, Yangsan, Korea
}

\author{
미래의 수면의학: 모바일 헬스와 빅데이터 \\ 김지영 ${ }^{1}$, 조재욱 ${ }^{2}$

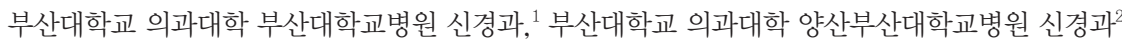

\author{
Received November 30, 2018 \\ Revised April 12, 2019 \\ Accepted May 7, 2019 \\ Address for correspondence \\ Jae Wook Cho, MD, PhD \\ Department of Neurology, \\ Pusan National \\ University Yangsan Hospital \\ 20 Geumo-ro, Mulgeum-eup, \\ Yangsan 50612, Korea \\ Tel: +82-55-360-2122 \\ Fax: $+82-55-360-2152$ \\ E-mail: sleepcho@pusan.ac.kr
}

Sleep is well known to be important to health and well-being, creativity, memory consolidation, and cognitive functions. However, sleep disorder patients sometimes had some limitation to get proper diagnosis and treatments. Now we live in an era of big change, so called the Fourth Industrial Revolution, which is characterized by mobile internet connectivity and artificial intelligence. Sleep medicine also started to change to patients-centered medicine with technical enhancement. To date, lots of smartphone applications and wearable device for monitoring sleep have appeared but not been validated enough against polysomnography. As another topic, big data receives lots of attention among sleep specialists. It is believed that big data would provide the basis of personalized healthcare. Here, we will discuss about new trend of sleep medicine involving mobile health such as telemedicine, smartphone, wearable device, and big data.

J Sleep Med 2019;16(1):1-10

\section{서 론}

좋은 수면은 건강을 유지하고 삶의 질을 높게 유지하기 위한 필수 조건이다. 그러나 문명이 발달하고 사회가 복잡해 지면서 오히려 현대인들은 야간 근무시간이 길어지거나 교 대근무를 하게 되었고 통근하는 데 더 많은 시간을 소요하 게 되어, 과거와 비교해 양적으로 수면시간이 부족하거나 질 적으로 좋지 못한 잠을 자는 경우가 많다., 양질의 수면을 취하기 힘든 문제는 개인의 차원을 넘어서 사회, 국가적인 부담이기도 하다. 호주에서는 수면장애가 국가 질환 부담의 $1.4 \%$ 로 추정되며, ${ }^{3}$ 미국 질병통제예방센터(Centers for Disease Control and Prevention)에서는 부족한 수면이 공적 건 강 문제임을 공식적으로 선언하였다. ${ }^{4}$

그러나 시간과 공간의 제약으로 의료 접근성이 제한되거 나 고비용 등의 문제로 수면장애를 적절하게 평가하기 힘든

This is an Open Access article distributed under the terms of the Creative Commons Attribution Non-Commercial License (https://creativecommons.org/licenses/by-nc/4.0) which permits unrestricted non-commercial use, distribution, and reproduction in any medium, provided the original work is properly cited.
경우가 많으며, 장기적인 추적관찰을 요하는 수면장애 특성 상 올바른 치료를 유지하기 힘든 면이 있다. 과학기술과 인 터넷의 눈부신 발전으로 기존의 의료 서비스 제공 방식에 변 화가 시작되었으며 의료진 중심에서 스마트폰 등의 장비를 활용한 환자 중심의 의료로 변화가 시작되고 있다. 그리고 이로 인해 수많은 사람들의 데이터가 축적되면서 형성되는 빅데이터 또한 의료계의 화두로 자리매김하고 있다.

본 종설에서는 기술의 발전이 가져온 변화와 함께 앞으로 진행될 수면의학의 미래를 모바일 헬스를 이용한 수면의학, 그리고 빅데이터로 나누어 살펴보고자 한다.

\section{모바일 헬스와 수면의학}

전통적으로 의료 서비스는 제공자와 수혜자가 병원 혹은 기타 장소에서 만나 주고받는 형태였지만 정보통신기술(information \& communication technology)과 생체신호 센서 기술이 발전함에 따라 스마트폰 등 무선인터넷 접속이 가능 한 첨단 장비를 통해 스스로 경과를 기록하거나 자가 치료 
(self-management)의 형태로 제공되는 모바일 헬스(mobile health)의 수요가 높아지고 있다. 모바일 헬스는 European Commission의 정의에 따르면 "medical and public health practice supported by mobile devices, such as mobile phones, patient monitoring devices, personal digital assistants, and other wireless devices"를 일컫는다. ${ }^{5}$

모바일 헬스의 장점으로는 첫째, 데이터 관리를 통해 조기 에 이상을 발견하여 질병을 예방하고 삶의 질을 높일 수 있 으며, 둘째, 시간과 비용을 절약하여 좀 더 효율적이고 적합 한 의료 서비스를 제공할 수 있으며, 마지막으로 과거에 비 해 환자가 자신의 건강 관리에 능동적으로 참여할 수 있게 되었다는 점 등을 생각할 수 있다. ${ }^{5}$

특히 수면질환의 경우 증상이 평생 혹은 장기적으로 지속 될 수 있고, 임상 경과 파악이 설문지 등 병력 청취를 통해 이루어지는 경우가 많기 때문에 타 분야와 비교했을 때 모바 일 혹은 첨단기기를 이용한 자가 치료의 활용 범위가 더 넓 다고 할 수 있다. 수면 패턴 분석이나 무호흡에 대한 continuous positive airway pressure(CPAP) 치료 데이터를 환자 스스로 확인하고 치료 중심 역할을 한다는 점에서 수면의학 의 새로운 시대가 열렸다는 평가도 있다. ${ }^{6}$

\section{Telemedicine을 이용한 수면장애의 진단과 치료}

Telehealth가 환자 외에도 '원거리에 있는 사람에게 헬스 케어를 제공하고 보조하는 전자정보와 통신기술의 이용'이 라는 의미로 임상적이거나 비임상적인 활동 모두를 포괄하 는 광의의 개념이라면, telemedicine은 좀 더 좁게 '환자와 제공자 간의 동시적 혹은 비동시적 직접적인 상호작용’으로 구체적인 의미를 가지고 있다. 여기서 동시적이란 의미는 실 시간으로 환자의 정보를 인터넷 혹은 전화를 통하여 전달한 다는 뜻이며, 비동시적은 $\mathrm{CPAP}$ 기계처럼 데이터를 저장하 였다가 전송한다는 의미다. ${ }^{7}$

국외에서는 수면의학에서 telehealth를 진단부터 치료 모 니터링까지 여러 단계에서 이미 시도하고 있으며, ${ }^{8}$ 특히 수 면장애 중 유병률이 높은 폐쇄수면무호흡과 불면증의 치료 에 이러한 telemedicine을 효과적으로 많이 활용하려는 노 력이 시도되고 있다.

\section{폐쇄수면무호흡}

폐쇄수면무호흡 영역에서 telemedicine은 원격 진단, 원 격 상담, 그리고 $\mathrm{CPAP}$ 의 원격 titration 크게 세 가지 영역으 로 나누어서 살펴볼 수 있다. 8
원격 진단

아직까지 수면무호흡을 진단하는 가장 정확한 방법은 수 면다원검사다. ${ }^{9}$ 그러나 수면다원검사는 환자가 집이 아닌 검 사실에서 잠을 자야 하고, 비용이 비싸며, 하루에 많은 환자 를 검사할 수 없는 등의 단점이 있다. 이러한 문제 때문에 1980년대부터 이동식 수면다원검사 기계를 보조적으로 사용 해 왔으나, 기계에 익숙하지 않은 환자가 집에서 직접 착용 하는 방식이다 보니 검사가 제대로 이루어지지 못하고 기록 실패율이 4.7 20\%에 이를 정도로 높은 것이 단점이었다. 10,11 이러한 단점을 줄이기 위해 숙련된 검사자가 원거리에 위치 한 검사실에서 인터넷 파일전송 프로토콜(file transfer protocol)을 통해 주기적으로 환자의 데이터를 체크하면서 문제 가 있으면 환자에게 전화로 연락하는 등의 방법이 시도되었 다. ${ }^{12-14}$ 최근에는 블루투스나 $\mathrm{WiFi} / 3 \mathrm{G}$ 인터페이스 등을 사 용해 수면다원검사 장비가 좀 더 쉽고 빠르게 인터넷에 연결 되어 검사자가 원격으로 쉽게 조종하여 검사 기록률을 높일 수 있었다는 연구결과도 있었다. 15,16 이전의 일반적인 홈모니 터링과 비교하면 원격 조종을 통한 검사는 분명 높은 기록 성공률을 보여주지만, ${ }^{17}$ 아직까지 일부 기술적인 문제와 첨 단 기술을 장착한 기계의 가격 문제로 현실적으로 체감할 수 준의 큰 검사방법의 변화는 나타나지 않고 있다.

이제 대한민국에서도 전통적인 방식의 수면다원검사의 건강보험 적용이 부분적으로나마 시작되었고 이동식 수면 검사 장비를 통한 검사의 보험 적용 범위에 대해서도 추후 논의가 될 예정이다. ${ }^{18}$ 어느 정도 레벨의 장비를 이용한 검사 를 인정할 것인지, 아직 국내에서는 활발하지 않지만 telemedicine을 장착하여 검사자가 개입하는 검사에 대해 별도 로 수가 산정을 할 것인지 등에 대한 폭넓은 토의가 필요할 것으로 사료된다.

\section{원격 상담}

폐쇄수면무호흡을 치료하기 위한 positive airway pressure(PAP) 사용에 있어 가장 중요한 요소 중 하나는 꾸준히 $\mathrm{PAP}$ 을 사용해야 한다는 점이다. 일반적으로 하루 4시간 이 상 사용하는 날이 전체 기간의 $70 \%$ 이상 혹은 1 주일 중 5 일 이상이 되면 적정한 순응도라고 정의 내리고 $\mathrm{PAP}$ 의 효과가 나타난다고 알려져 있으며, $19,203,100$ 명의 양압기 이용 환자 를 대상으로 한 코호트 연구에서는 하루 5 6시간 이상 꾸준 히 사용하는 것이 심혈관계 합병증 예방에 도움이 된다는 결과를 보여줬다. ${ }^{21}$ 그러나 불편함, 무관심, 피부 문제 등 여 러 가지 원인으로 사용률이 떨어지는 경우가 많으므로 지속 적인 추적관찰과 상담이 필수적이다. 최근 PAP 기계에는 센 서가 부착되어 있어 무호흡-저호흡 지수, 공기의 압력, leak- 
age, 마스크 사용시간 등이 기록되므로, 이 데이터를 확인하 여 양압기 사용 시 적정 압력과 순응도를 대략적으로 확인 할 수 있다.22 이러한 데이터는 메모리카드에 저장되어 다운 로드할 수 있어 환자 혹은 의료진에게 원격으로 전송이 가 능하므로 환자-의사 대면 진료 없이도 상담이 가능하다. ${ }^{23}$ 기술이 발전하면서 무선으로 PAP 기계의 데이터가 매일 중 앙 서버에 데이터를 전송하여 메모리카드가 필요 없는 장비 들도 등장하였다. Isetta 등이 시행한 최근 연구에 따르면 영 상 컨퍼런스를 통해 $\mathrm{CPAP}$ 사용법에 대한 교육을 시행한 경 우와 일대일 대면 교육을 했을 때 교육 효과 면에서 큰 차이 가 없었으며, $95 \%$ 의 환자가 Telemedicine을 이용한 CPAP 추적관찰에 만족하였다. ${ }^{24} \mathrm{CPAP}$ 을 2 개월간 사용함에 있어 무선 telemedicine을 이용하여 모니터링한 군과 기존의 방 식대로 추적관찰한 군 각각 20명씩 비교한 파일럿 연구에서 는 데이터를 환자가 바로 확인하고 수면 전문가로부터 조언 을 들을 수 있는 텔레모니터링 군이 기존 방식으로 추적관 찰한 군에 비해 비록 통계적인 유의성은 없었으나 사용시간 과 사용 일수에서 오히려 더 나은 결과를 보였다(각 군의 사 용시간 4.1 시간, 2.8 시간). ${ }^{25}$

1,455 명의 환자를 대상으로 한 대규모의 연구에서는 웹으로 CPAP 사용 교육(web-based education)을 하는 것은 CPAP 사용률을 크게 향상시키지 못하였으나, 자동으로 피드백 메 시지를 보내는 텔레모니터링은 환자가 지속적으로 $\mathrm{CPAP}$ 을 사용하도록 하는 효과가 있었다. ${ }^{26}$ 그러나 의료진이 이 데이 터를 확인 후 $\mathrm{CPAP}$ 사용에 관한 문제를 발견했을 때 환자 에게 전화로 안내하거나 상담을 할 경우 아직까지는 이에 대한 보상 체계가 마련되어 있지 않으므로 현재로서는 데이 터를 수집하는 정도에 머무를 수밖에 없다. 따라서 기술적인 발전과 더불어 제도적인 보완이 이루어진다면 telemedicine 의 취지에 맞는 좀 더 편리한 의료 서비스가 가능할 것으로 기대된다.

\section{$\mathrm{CPAP}$ 원격 titration}

$\mathrm{CPAP}$ 의 적정 압력을 정하기 위한 titration을 원격으로 진행할 수 있다면 환자가 집에서 수면을 취할 수 있고 비용 을 절감할 수 있는 장점이 있다. Dellaca 등은 $\mathrm{CPAP}$ 을 처음 사용하는 20명의 중증 폐쇄수면무호흡 환자에게 CPAP 압 력을 titration하는 연구를 진행했다. ${ }^{27}$ 결과적으로 기계의 압 력, leakage, airflow 등의 데이터를 원격으로 보내고 이에 맞 춰 압력을 조절할 수 있는 telemedicine 장비를 장착한 $\mathrm{CPAP}$ 을 사용한 경우와, 수면 검사실에서 titration한 경우 적정 압 력 수치의 차이가 없었다(각각 $9.15,9.2 \mathrm{~cm} \mathrm{H}_{2} \mathrm{O}$ ). 그러나 최 근 자동으로 압력을 정하는 autotitration의 정확도가 높아지
면서 수면 관련 전문가가 원격으로 압력을 조절하는 것보다 집에서 기계가 자동으로 압력을 맞추는 것이 더 효율적이고 비용 절감 면에서도 장점이 있을 것으로 고려되고 있다. 그 러나 autotitration이 금기증인 환자들도 있으며, ${ }^{28}$ 적정 압력 을 맞추는 데 실패하는 경우도 있으므로 환자에 따라 선택 적으로 고려할 필요가 있다.

\section{불면증}

불면증은 연구에 따라 대체적으로 전체 인구의 약 10 30\% 가 겪고 있으며 이 중 50\%가 만성적인 흔한 수면장애다. ${ }^{29}$ 국 내의 경우 전화 설문조사로 진행된 연구에서 $22.8 \%$ 가 불면 증을 호소하고 있었으며 특히 고령의 인구에서 심한 것으로 조사되었다. ${ }^{30}$ 이러한 만성 불면증의 치료로 효과적이고 안 전한 인지행동치료가 필수적으로 먼저 고려되어야 하나, 국 내에서는 활용도가 아직 낮은 편이며 현 의료보험 체계하에 서 수면제 등 약물치료를 선호하는 경향이 있다. ${ }^{11}$ 2015년 국 내불면증치료 실태 및 건강영향조사에서 불면증에 대해 인 지행동치료를 시행한 환자는 전체의 $34.83 \%$ 였고, 치료에 대 한 만족도는 매우 만족 5.62\%, 만족스러움 $28.9 \%$ 로 높지 않 았다. 그 이유로는 진료시간 부족, 시행방법에 대한 정보 부 족, 효과 부족 등을 꼽았다. ${ }^{31}$

불면증 인지행동치료(cognitive behavior therapy)가 telemedicine 영역에서도 시도되고 있다. 전통적인 불면증 인지 행동치료는 전문 의료인과 만성 불면증 환자가 직접 대면하 며, 수면 제한 요법(sleep restriction), 자극 조절 요법(stimulus control therapy)을 실시하고 잘못된 수면 습관을 교정 하여 불면증 증상을 완화시키기 위한 방법이다. ${ }^{32}$ 불면증 인 지행동치료를 telemedicine을 통해 시행하는 방법이 현재 많이 연구되고 있고, 미래에는 현재보다 더 빈번하게 사용되 고 적용될 가능성이 높다. 그 이유로는 많은 수의 불면증 환 자에 비해 불면증 인지행동치료를 잘 훈련받은 전문 의료인 수가 상대적으로 부족하다는 점과, 불면증 인지행동치료 시 정해진 시간에 의료기관을 반복해서 방문해야 하는 번거로 움과 이에 따르는 비용의 문제, 불면증 인지행동치료 중 정 형화되고 표준화된 치료 내용은 웹 기반의 인터넷을 통해서 도 제공될 수 있다는 점 등을 생각해 볼 수 있다. ${ }^{33}$

불면증 인지행동치료에서 시도된 telemedicine 방법은 미 리 만들어지고 저장된 정보를 웹 기반의 인터넷을 통하여 제공하거나, 실시간으로 화상 시스템을 통하여 의료진과 정 보를 주고받을 수 있는 쌍방향의 형태로 시도되고 있다. 한 명의 의료진이 한 명의 환자를 볼 수도 있고 웹을 기반으로 하여 한 번에 여러 환자를 만날 수도 있다. 원격 화상 시스템 을 이용하면 의료진과 환자는 실시간 비디오 화면을 통하여 
정보를 서로 주고받을 수 있고, 병력 청취를 할 수 있으며, 환자의 진찰 소견은 환자와 함께 있는 다른 의료인(patient presenter)의 보조를 받을 수 있다. 마지막으로 무선인터넷 보급과 웨어러블 디바이스의 소형화 및 발전에 따라 이들을 이용해서 장소에 구애받지 않는 형태로도 시도되고 있다.

45명의 만성 불면증 환자를 대상으로 웹 기반의 불면증 인지행동치료 효과를 알아보기 위해 실시한 연구에서 9주간 의 웹 기반 불면증 인지행동치료를 하였던 군은 치료 전후 불면증 심각 척도(Insomnia Severity Index) 점수가 15.73에 서 6.59로 의미 있게 감소하였으나, 대조군은 16.27 에서 15.50 으로 유의한 변화를 보이지 않았다. ${ }^{34}$ 또한 불면증 심각 척도 의 개선은 웹 기반 불면증 인지행동치료군에서 치료 중단 6 개월 후에도 지속되는 것이 확인되었다. 118 명의 만성 불면 증 환자를 대상으로 한 연구에서는 6주간의 웹 기반 불면증 인지행동치료군은 대조군과 비교하여 피츠버그 수면의 질 평가 척도(Pittsburgh Sleep Quality Index)가 3.5점 감소하 였으나, 대조군은 의미 있는 변화가 없었다. ${ }^{35} 18$ 세 이상 164 명의 만성 불면증 환자를 대상으로 실시된 무작위 배정 위 약-대조군 연구도 웹 기반의 불면증 인지행동치료군은 다 른 군들에 비하여 우수한 수면 효율 향상을 보였다. 웹 기반 의 불면증 인지행동치료와 화상 진료방법을 사용한 불면증 인지행동치료 사이의 비교 연구에서는 두 방법 간에 불면증 에 대한 유사한 치료 효과가 있었다. 불면증 인지행동치료 전후 웹 기반의 불면증 인지행동치료군은 불면증 심각 척도 점수가 5.94 감소하였고, 화상 진료군은 7.73 감소하였으나, 두 군 사이에서 불면증 인지행동치료에 따른 불면증 심각성 척도 감소는 유의한 차이가 없었다. ${ }^{36}$ 웹 기반의 불면증 인지 행동치료에 대한 메타 분석에서도 웹 기반의 인지행동치료 군은 대조군과 비교하여 불면증 심각성도는 유의하게 감소 하고, 총 수면시간에서는 유의한 향상을 보였다. 또한 치료 자와 직접 대면하여 실시하는 전통적인 불면증 인지행동치 료와 비교에서도 치료 전후 수면 효율, 총 수면시간, 불면증 심각성 척도의 변화에서 차이를 보이지 않았다. ${ }^{37}$ 최근 국내 에서는 스마트폰과 웨어러블 기기를 이용하여 4주간 불면증 인지행동치료를 시도했던 선행연구가 있었고, 참여자들은 4 주 뒤 불면증 심각성 척도, 피츠버그 수면의 질 평가 척도, 수면 잠복기에서 유의한 개선을 보였다. ${ }^{38}$ 이러한 연구결과 는 전문 인력의 중재 없이도 잘 디자인된 플랫폼에서 환자 주도적인 환자 중심의 인지행동치료로 만성 불면증의 증상 을 상당 부분 개선할 수 있다는 희망을 주었다.

인터넷을 통한 불면증 인지행동치료의 효과를 기존 발표 된 15 개의 문헌으로 메타분석하여 연구한 결과는 기존의 대 면 방식과 비교해도 뒤떨어지지 않을 만큼 불면증 치료에
효과적이라는 것을 보여주었다. ${ }^{39}$ 1 2주 사이 비교적 짧은 기간 반복적으로 의료기관을 방문해야 하는 비용과 시간 소 모적인 전통적 불면증 인지행동치료의 특징을 감안할 때 향 후에도 telemedicine을 이용한 불면증 인지행동치료에 대한 시도는 증가할 것으로 생각된다.

\section{스마트폰 애플리케이션}

최근 스마트폰의 보급률이 매우 가파르게 상승하여 2017 년 기준 대한민국은 성인 인구의 $88 \%$ 가 스마트폰을 사용하 고 있어 세계 최상위권이며, 미국은 약 $77 \%$ 의 성인이 사용 하고 있다. ${ }^{40}$ 과학기술정보통신부의 '2018년 무선통신서비스 가입회선 통계' 자료에 따르면 스마트폰 회선 가입자 수가 5 천만 명을 넘을 정도로 스마트폰이 대중화가 되었다. ${ }^{41}$ 또한 2012년 미국에서 시행한 설문조사 연구에서는 전체 대상자 의 69\%가 스마트폰이나 웨어러블 디바이스, 혹은 종이로 기 록하는 등의 방법으로 체중, 식이 조절, 다이어트 등 건강 지 표를 기록한다고 하였으며, 이 중 $21 \%$ 는 첨단 테크놀로지를 이용해서 관리한다고 응답하였다. 2 이렇게 스마트폰의 사용 이 익숙해지고 건강에 대한 관심이 높아지면서 수면과 관련 된 스마트폰 애플리케이션에 대한 대중의 관심 또한 매우 높고 애플리케이션의 수가 빠르게 늘어나고 있지만, 아직까 지는 질적 우수성과 콘텐츠, 그리고 수면 자가 조절의 관점 에서 평가했을 때 평균 이상의 점수를 획득한 애플리케이션 이 적은 편이며, 대부분의 기능이 수면을 기록하고 데이터를 사용자에게 보여주는 데 초점이 맞춰져 있다. ${ }^{43}$ 또한 이러한 애플리케이션들이 의료 목적으로 임상에서 이용되기보다는 사용자의 호기심 혹은 재미를 위해 소비되는 경우가 더 많다.

그리고 애플리케이션을 통해 계산되고 제시되는 consumer sleep technologies 자료들이 실제 수면다원검사와 비교해 어느 정도 믿을 만한지 유효성(validation)에 대한 연구가 매 우 적은 상황이다. 현재까지 발표된 애플리케이션의 유효성 에 관한 연구들은, 아직 애플리케이션으로 얻은 수면 관련 척도들이 수면다원검사의 결과와 상관관계가 높지 않으며 정확한 수면단계를 반영하지 못해, 애플리케이션을 임상적 평가 도구로 유용하게 사용하기는 아직 이르다는 결과를 보 여주었다. ${ }^{44-46}$ Bhat 등이 20명의 성인을 대상으로 한 수면다 원검사와 수면 애플리케이션 Azumio(Redwood City, CA, $\mathrm{USA}$ )의 비교연구에서는 수면과 각성을 구별하는 기능은 좋 은 상관관계를 보였으나, 수면 효율, 수면 잠복기, 그리고 수 면 구조 비율 측정치가 서로 다른 결과를 보였다. ${ }^{44}$ 2013년 발표된 Google Play Store와 Apple App Store에서 다운로드 하여 사용할 수 있는 애플리케이션에 관한 연구에서도 과학 적 근거에 기반한 수면 관련 애플리케이션은 아직 없는 것 
으로 결론 지었다. ${ }^{47}$ 또한 지금까지 발표된 연구결과들은 거 의 대부분 정상인을 대상으로 한 것으로, 수면장애 환자에게 애플리케이션이 얼마나 유효한지는 좀 더 연구가 되어야 하 는 상황이다.

특히 동일하게 수면 중 움직임을 체크하는 같은 원리로 수면을 모니터링하는 액티그래피의 유효성이 이미 검증된 것에 비해 영업기밀 등의 이유로 좀 더 폐쇄적인 알고리듬 을 가진 스마트폰 애플리케이션은 아직 유효성의 검증이 더 욱 요구된다..$^{8}$ 이를 위해서 소프트웨어 기술자, 데이터 전문 가, 그리고 임상수면 전문가 등이 함께 종합적으로 연구 노 력할 필요가 있다. ${ }^{47}$

이렇게 애플리케이션의 유효성 검증에 관한 연구가 부족 한 관계로 미국 식약청(Food and Drug Administration, FDA) 의 허가와 관리 또한 활발하게 이루어지는 편은 아니며, 세 계 수면의학의 중심이라 할 수 있는 미국수면의학회에서도 이를 반영하여 모바일 애플리케이션 등 Consumer sleep technologies가 아직까지는 수면장애의 진단과 치료에 이용될 수 는 없다는 입장을 발표했다. ${ }^{49}$ 현재로서는 적절한 임상적 평 가를 함께 시행하여 의사와 환자가 서로 소통하는 의학적 도구로서만 이용 가능하며, 향후 유효성 검증이 이루어지고 데이터 혹은 알고리듬에 쉽게 접근이 가능해야 하며, $\mathrm{FDA}$ 의 감독이 철저히 이루어질 필요가 있다는 내용이었다. $\mathrm{FDA}$ 는 2013년 의료용 모바일 애플리케이션에 대한 관리 지침을 발 표한 이후 지속적으로 업데이트를 하고 있는데, 2018년 현 재 수면 관련 애플리케이션들은 일반적으로 위험이 낮은 군 으로 분류가 되어 있다. ${ }^{50}$ 대한민국에서는 2013년 식품의약 품안전처에서 ‘모바일 의료용 앱 안전관리 지침'을 발표하여 애플리케이션의 허가, 품질 및 사후 관리 방안을 제시하였 다. ${ }^{51}$ 이 지침서는 애플리케이션을 크게 의료기기에 해당하 는 모바일 의료용과 해당되지 않는 것으로 분류하여, 의료기 기에 해당되는 경우 제품 허가 신청 시 일반적인 의료기기 처럼 '의료기기 허가 - 신고 - 심사 등에 관한 규정'을 따르도 록 되어 있다. 따라서 제조업자는 모바일 의료용 애플리케이 션에 대해 식약처에서 작성한 "의료기기 소프트웨어 밸리데 이션 가이드라인(2007.3)”을 따라 문서화해야 하고, 허가심 사 신청 시에는 소프트웨어 요구사항 명세서, 설계 명세서, 그리고 소프트웨어 검증과 확인에 관한 기술 문서와 첨부 자료를 제출해야 한다. 또한 필요에 따라 임상 자료에 관한 검토가 필요할 수 있도록 규정하고 있다. 그러나 이러한 복 잡한 절차에 비해 어떤 경우에 임상 자료가 필요한지, 어떤 기기가 어느 항목에 포함되는지 등에 대한 세부적인 분류 없이 대략적인 설명과 예시만 제시되어 있기 때문에 $\mathrm{FDA}$ 의 자세한 항목 분류와 기술에 비하면 아직 내용이 빈약하며, 애
플리케이션 개발자의 입장에서는 혼란스러울 여지가 있다. 이후 법 개정을 통해, 모바일 의료용 애플리케이션을 휴대전 화나 가전제품에 탑재할 경우 허가 취득 후 의료기기 판매 업 신고를 하지 않아도 되도록 규정을 완화하였으나, 지침서 자체는 2013년 이후 개정되지 않아 여전히 추가적인 보완이 필요할 것으로 보인다.

\section{웨어러블 디바이스}

수면을 취하는 동안 신체에서 떨어진 상태로 옆에 두는 스마트폰의 애플리케이션에 비해, 직접 손목에 차고 수면 데 이터를 측정하는 웨어러블 디바이스의 경우 여러 생체신호 추적에 대한 연구는 비교적 활발히 이루어졌으나 수면의 세 부적인 측정에 대해서는 역시 유효성이 아직 많이 연구되지 는 못하였다. 상용화가 된 웨어러블 디바이스 중 세계적으로 많이 사용되고 있는 애플 워치(Apple Watch; Apple, $\mathrm{Cu}^{-}$ pertino, CA, USA), 핏빗(Fitbit, San Francisco, CA, USA), 조본(Jawbone, San Francisco, CA, USA), 샤오미 미밴드 (Mi Band; Xiaomi, Beijing, China), 그리고 갤럭시 워치 (Galaxy Watch; Samsung, Seoul, Korea) 등은 손목에 시계 처럼 착용하여 생체신호 측정 및 수면리듬을 파악한다. 이러 한 장치들은 궁극적으로는 내장된 accelerometers를 이용하 여 신체의 움직임을 측정하는 액티그래피라는 점에서 뇌파, 근전도, 안구운동 등의 생체신호로 수면을 모니터링하는 수 면다원검사와 차이점이 있다. 착용자의 움직임과 심박동을 측정 분석하여 수면을 잘 취하였는지, 깊은 잠을 잤는지, 더 나아가 수면의 단계별로 어느 정도 잠을 잤는지 평가한다. 움직임에 의존하다 보니 실제 수면과 다르게 인식되기도 하 며, 미가공 데이터(raw acceleration data)를 수면 분석에 적 합하도록 가공하는 알고리듬이 디바이스마다 다르기 때문 에 수면 분석 결과물에 나타날 수 있다. ${ }^{52}$

세계시장 점유율은 핏빗이 전체의 과반 이상을 차지하였 으나 2016년 선적 기준으로는 전체 시장의 $47 \%$ 를 기록하여 여전히 우위를 점하고 있지만 조금씩 줄어드는 추세다. ${ }^{53}$

대표적인 웨어러블 디바이스 6개 각각의 생체신호 측정 정확도를 알아본 최근 연구에서는 대부분의 디바이스가 서 로 수면시간을 비슷하게 나타내는 일치율을 보였으나, 수면 다원검사 결과와 디바이스별로 비교하지 않고 '애플 워치2' 를 기준으로 하였다는 점과 단순한 수면시간 비교만 하였다 는 점에서 아쉬움이 있다. ${ }^{54}$ 핏빗과 수면다원검사의 일치율 을 알아본 최근 연구에서 일반 성인을 대상으로 하였을 때 수면을 인지하는 정확도는 $96 \%$, 각성은 $61 \%$ 였으며, 얕은 수 면과 렘수면 정확도는 각각 $81 \%, 74 \%$ 로 높은 반면 깊은 수 면인 서파수면은 $49 \%$ 에 불과했다. ${ }^{55}$ 측정 변수마다 차이가 
있어 비교적 정확한 변수도 있고 그렇지 않은 변수도 있기 때문에 기술적으로 보완하면 일치율을 높일 수 있을 것으로 기대된다. 그런데 폐쇄수면무호흡을 가지고 있는 3 18세의 소아 환자를 대상으로 하였던 연구에서는 핏빗이 수면다원 검사에 비해 전체 수면시간을 과도하게, 각성시간은 반대로 적게 표시하여 유효성이 만족스럽지 못하였다. ${ }^{56}$ 향후 연령 별로, 특정 수면질환별로 일치율과 유효성을 검증하는 연구 가 필요하다.

대중화된 대부분의 웨어러블 디바이스는 손목에 착용하 는 형태지만 머리에 착용하는 헤어밴드 형태의 디바이스도 존재했다. Zeo Inc.(Newton, MA, USA)에서 수면 측정용으 로 개발한 Zeo는 머리에 착용하는 무선 헤어밴드로, 정상인 을 대상으로 수면다원검사와의 유효성을 확인한 연구에서 수면/각성은 90\% 이상, 수면단계 측정에서는 $70 \%$ 이상의 일치율을 보여 기존의 수면다원검사보다 간단하게 수면을 측정할 수 있을 것으로 기대되었다. ${ }^{39}$

하지만 센서가 신체에 접촉되어야만 측정이 가능한 웨어 러블 디바이스는 잠을 자기 전 기구를 착용해야 하는 번거 로움을 동반하며, 신체 접촉을 선호하지 않거나 불가능한 사 람에게는 적합하지 않다. 최근 Massachusetts Institute of Technology의 교수들과 연구자들이 주축이 되어 설립한 Emerald project는 무선으로 생체신호를 수집하고 클라우드 플랫폼(cloud platform)에 데이터를 저장 후 인공지능을 이 용한 머신러닝(machine learning)으로 데이터를 분석하는 과정에 집중하고 있다. ${ }^{57}$ 특히 수면과 관련해서 라디오 주파 수 시그널을 이용해 별다른 센서 없이 무선으로 호흡, 맥박, 몸의 운동 등을 감지하여 수면 효율, 수면 잠복기, 침대에 누 워 있는 시간, 총 수면시간 등의 수면 측정 관련 변수를 측정 하는 EZ-sleep을 선보였는데, 변수별로 기존의 수면검사와 비교해 수분의 차이밖에 나지 않을 만큼 높은 정확도를 보 여주었다. ${ }^{58}$ 또한 주파수만으로 수면단계를 예측함에 있어서 도 $79 \%$ 의 일치율을 보여 과거의 수치에 비해 비약적인 향상 을 보여주었다. ${ }^{59}$

\section{Telemedicine의 제한점들}

과학 기술의 발전과 더불어 첨단 장비가 개발되면서 다양 한 방식의 telemedicine이 시도되고 기계의 사용도 편리해졌 지만 이와 더불어 비용과 가성비, 그리고 사용자로부터 수집 한 데이터를 어떻게 관리할 것인지 역시 극복해야 할 과제 다. 애플리케이션과 웨어러블 디바이스의 지속적인 업데이 트가 가능하여 이용자가 보다 편리하고 정확하게 사용할 수 있도록 비용을 마련해야 하는데, Zeo의 경우 수익모델을 찾 지 못해 사업을 중단할 수밖에 없었으며, Emerald project
또한 상용화가 아직 진행되지 못하고 있어 실제 임상 현장 에서 적용하기까지는 시간이 더 필요할 것으로 예상된다. 또 한 수면리듬을 측정하는 애플리케이션인 SleepBot(SleepBot LLC, DE, USA)은 유럽연합의 일반데이터보호규칙(General Data Protection Regulation)을 준수하지 못하여 사용이 불가능한 상태다. ${ }^{60}$ 개인정보의 중요성이 갈수록 강조되므로 애플리케이션을 개발, 운영할 때는 이러한 데이터 관리에도 주의를 기울여야 한다.

특히 국내에서는 원격 진료에 대한 사회적 합의가 심도 있게 이루어지지 않았고, 원격 진료로 인한 부작용에 대한 대비도 부족하며 이에 대한 법적 장치도 과도기 시점임을 고려할 때, 수면장애 역시 원격 진료 영역에서 다른 질환과 비슷한 변화를 따를 것으로 예상된다.

\section{빅데이터(Big Data)}

인간의 생체신호를 측정하는 각종 센서와 인터넷의 발달 로 기존과는 다른 많은 양의 정보를 수집, 저장, 분석할 수 있는 환경이 되었다. 이러한 많은 양의 축적된 자료를 활용 한 연구, 즉 빅데이터를 활용한 연구가 의료 분야에서도 시 도되고 있다. 빅데이터를 이용한 연구는 개인 간의 차이 및 각종 변수들 간의 복잡한 상호 작용을 탐구하여 맞춤의학 및 정밀의학의 길을 열어주는 중요한 방법으로 거론되고 있 다. ${ }^{61,62}$ 현재 의료 분야에서 활용되는 빅데이터의 특징으로 는 3'V', 즉 자료의 양(volume), 속도(velocity), 다양성 (variety)이 포함된다. ${ }^{63}$ 빅데이터의 방대한 양의 자료는 분석 시 통계학적 검정력을 향상시키고, 이 점은 하위집단 분석 시 더욱 유용하게 활용될 수 있다. 속도는 자료의 생성과 분석 되는 빠르기를 의미한다. 빅데이터에서 이용되는 자료의 생 성과 분석은 거의 실시간으로 이루어져, 신속한 질병의 확인 과 대처를 하게 해 줄 수 있다. 예를 들어 감염병의 경우 스 마트 폰 혹은 인터넷을 기반으로 한 빠른 자료 생성은 인구 집단의 건강 상태 변화를 즉각적으로 파악할 수 있는 수단 으로 이용될 수 있다. 다양성은 다양한 정보원 혹은 형태의 자료를 뜻한다. 빅데이터 자료는 소셜 미디어, 의무 기록, 스 마트폰 혹은 이 모든 자료원의 조합으로부터 얻을 수 있어 기존 의무기록에 의존하던 자료들과는 차별화된 형태의 자 료를 얻을 수 있게 해 준다.

수면다원검사는 그 자체로도 많은 생체신호 데이터를 생 성하기 때문에 하나의 기관에서도 수년간의 자료를 바탕으 로 한 빅데이터를 형성하기가 용이하다. 그러나 수면장애 혹 은 설문항목 등과 함께 수면다원검사 자료를 분석해서 의미 있는 결과를 도출하기 위해서는 각각 수면장애의 특성과 표 
현형(phenotype)을 정확히 정의하는 작업이 중요하다. ${ }^{64}$

아직은 시작 단계지만 공용 데이터 세트 및 수면다원검사 자료를 바탕으로 빅데이터를 활용한 연구도 시도되고 있다. National Sleep Research Resource(NSRR)와 Montreal Archive of Sleep Studies(MASS)처럼 많은 양의 수면 관련 자 료를 대중들이 이용할 수 있도록 해주는 데이터 세트가 현 재 점차 증가하고 있다. 65,66 또한 수면다원검사는 풍부한 양 의 신체신호 정보를 확보할 수 있게 해주며 이러한 점들이 수면의학에서 빅데이터를 활용할 수 있는 환경을 만들어 주 고 있다. 앞서 언급한 NSRR은 National Institute of Health 에서 연구 기금을 지원한 코호트 연구 및 임상연구 자료를 이용하여 빅데이터를 만들었다. 각 연구자들의 연구 자료를 바탕으로 하여 빅데이터를 생성해 새로운 연구 가설의 확인 과 내용의 발견 및 반복연구(replication study)를 실시하여 선행연구들의 결과를 일반화하거나 검증을 하였다. ${ }^{65} \mathrm{NSRR}$ 자료에는 15 개의 코호트 연구와 3 만7천 명 이상이 포함된 임상연구의 자료가 포함되어 있다. NSRR 자료는 개인의 연 구 자료를 바탕으로 하여 커다란 데이터 세트를 만들었고 이를 통하여 나이 성별, 인종 간의 기준이 되는 수면 연구결 과를 제시하였고, 다양한 생체신호를 이용한 생체 표지자를 조사하였다. 또한 수면 부족과 다른 질환과의 관련성에 대하 여 평가하였다. 특히 여러 연구자들의 자료를 모아 분석함으 로써 각 개별 연구에서는 적은 연구 참여자 수가 갖는 한계 점과 낮은 빈도로 발생하는 증상 혹은 질환 평가에 대한 제 한점, 연구 참여자들의 비균질성으로 결론을 내릴 수 없는 문제점에 대해서도 답을 내리는 시도를 할 수 있었다.

$\mathrm{MASS}$ 는 검사실에서 실시된 수면다원검사 자료를 이용하 여 만들어진 자료이며, 이는 오픈 액세스(open-access) 형태 의 데이터 세트다. ${ }^{66}$ 수면질환 연구 시 수면다원검사는 중요 한 도구로 이용이 되며, 뇌파, 안전도, 근전도, 심전도와 같 은 많은 센서를 통하여 다양한 신체신호를 기록한다. 이렇게 기록된 신호를 수작업으로 분석하는 데는 많은 시간과 노력 이 필요하다. 이러한 문제를 극복하기 위해 기기에 의한 자 동 분석을 시도하고자 노력이 지속되고 있다. 그러나 각 연 구자마다 다른 알고리듬을 이용하여 연구를 진행하고 있어 각 연구에 대한 재현성이 떨어지고 각 연구마다 결과 비교 가 어려운 실정이다. 이를 극복하기 위해 MASS가 만들어졌 으며, 향후 보다 많은 자료가 모이고 연구에 활발하게 사용 된다면 빅데이터를 이용한 수면의학의 연구에 주요한 도구 가 될 것으로 생각된다.

국내의 경우 의료 분야에서 빅데이터를 이용한 연구가 이 제 시작하는 걸음마 단계일지라도, 연구자들에게는 많은 관 심이 가는 분야다. 현재 국내에서 활용되는 대표적인 빅데이
터 연구 자료는 국민건강보험공단에서 제공하는 건강보험 빅데이터와, ${ }^{67}$ 건강보험심사평가원에서 제공하는 보건의료 빅데이터 개방 시스템을 들 수 있다. ${ }^{68}$ 아직 이 자료를 이용한 수면장애 혹은 수면질환 관련 논문은 찾을 수 없으나 연구 보고서는 온라인으로 접근이 가능하다. 2015년 국민건강보 험 자료를 이용한 수면장애에 대한 보고서는 2004년부터 2013년까지 수면장애로 병원을 방문한 환자를 대상으로 수 면장애와 공존하는 정신질환, 심혈관질환, 뇌혈관질환, 치 매, 파킨슨씨병, 폐질환, 신장질환, 내분비질환, 위장질환, 알 레르기질환 및 기타 질환의 현황 및 특성을 분석한 연구로, 다양한 질환이 수면장애와 공존할 수 있으며 수면장애 유병 률과 중증도가 높은 노인을 대상으로 수면장애의 선별과 관 리가 필요함을 정책적으로 제안하였다. ${ }^{9}$ 건강보험심사평가 원의 2010 2015년 자료로 불면증의 유병률과 수면제 처방 현 황을 분석한 연구보고서도 있다. ${ }^{31}$

또 다른 국내 빅데이터 자료는 질병관리본부에서 진행하고 있는 한국인 유전체역학조사사업(The Korean Genome and Epidemiology Study)이다. ${ }^{70}$ 2001년부터 2014년까지 245,300 명의 자료를 수집하였고 2012년부터는 전면적 추적조사로 전환하였다. Kwon과 Shin은 이 사업의 하위항목인 안산의 지역사회 기반 코호트에 참여한 대상자 2,168 명을 대상으로 설문조사 자료를 구조방정식 모델링(structural equation modelling)으로 분석하여 규칙적인 운동이 과도한 주간졸림 증을 예방할 수 있음을 제시하였다. ${ }^{71}$

빅데이터는 방대한 자료를 바탕으로 진료와 연구에 많은 과학적인 근거를 제시해 줄 것으로 생각된다. 그러나 빅데이 터의 활용에도 몇 가지 제한점이 있다. 64,65 첫째, 빅데이터 자 료는 다양한 정보원으로부터 생성된 것일 수 있어 자료 형 태 및 용어의 표준화 과정을 거쳐야 한다. 의료 장비 회사 웨 어러블 디바이스 및 $\mathrm{CPAP}$ 등을 생산하는 다양한 장비 회사 로부터 오는 정보에 대한 수집과 통합 과정이 이루어져야 한다. 둘째, 많은 양의 자료가 반드시 양질의 자료가 아님을 명심해야 하며, 자료 분석 시 적절한 방법을 사용하지 않는 다면 잘못된 결과를 도출할 수도 있다. 연구자는 많은 양의 자료를 다루다 보니 그 자료가 가지고 있는 각각의 특성을 파악하지 못하는 일도 생길 수 있다. 예를 들어 빅데이터를 이용한 수면 분절에 대한 연구 시 유사한 수면 효율을 갖는 사람이라 하더라도 수면 분절을 일으키는 다양한 요인, 즉 무호흡의 정도, 수면 중 사지운동의 심각도, N1 수면과 같은 얕은 수면의 비율이 수면 분절에 영향을 미칠 수 있다. 따라 서 빅데이터를 이용한 연구에서 섣부른 일반화는 잘못된 결 과를 도출할 수 있으며 이러한 오류는 연구자가 자료의 특 성을 재차 살펴봄으로써 최소화할 수 있다. 셋째, 빅데이터 
의 생성과 유지는 많은 비용이 들 수 있다. 다양한 직종이 빅 데이터 생성과 유지에 필요하다. 여기에는 의료진과 더불어 정보 기술자, 컴퓨터 과학자, 통계학자, 수학자 등의 참여가 필요하다.

지금까지 살펴본 빅데이터를 이용한 연구는 기존 개인 연 구자들이 실시한 연구에서 답을 찾지 못한 사실에 대해 과 학적 근거를 제시해 줄 것으로 기대되고, 의학의 다른 분야 와 마찬가지로 수면의학에서도 맞춤의학과 정밀의학으로 가는 디딤돌을 놓아줄 것이다. 그리고 이를 위해서는 여러 분 야 전문가의 협업과 함께 많은 투자가 이루어져야 한다.

\section{결 론}

2016년 스위스 다보스에서 열린 세계경제포럼(World Economic Forum)에서 4차 산업혁명이란 단어가 화두가 된 이 후 전 세계의 산업 전반에 걸쳐 트렌드가 변화하고 있으며, 대한민국에서도 민간 기업과 정부 차원의 대응 전략을 마련 하고 있다. 아직 정확한 정의조차 뚜렷하지 않지만 컴퓨팅, 유전자, 나노 등의 모든 기술이 융합하고 물리학, 디지털, 생 물학이 상호 교류하여 파괴적 혁신을 유발하는 혁명이라 일 컬어진다. ${ }^{72}$ 여기엔 인공지능과 사물인터넷, 모바일, 그리고 빅테이터가 연관이 되어 사회 전반에 변화와 혁신을 가져올 것으로 예상되며, 의료 분야도 예외는 아닐 것이다.

의료에서의 이러한 변화는 환자가 병원에 방문하여 의료 서비스를 제공받는 전통적인 진료 방식과 검사에도 영향을 미칠 것이며, 특히 환자 본인이 생활습관을 변화시키고 장기 적으로 추적관찰하는 것이 필수적인 수면장애의 경우 진단 과 치료에 보다 긍정적인 방향으로 작용할 것이다. 또한 엄 청난 규모의 빅데이터를 바탕으로 한 연구는 환자 특성에 맞는 합리적이고 세심한 치료 방향 설정에 많은 도움이 될 것으로 기대된다.

아직 사물인터넷, 스마트폰 애플리케이션, 웨어러블 디바 이스, 그리고 빅데이터를 이용한 수면장애 연구가 많이 진행 되어 있지 않으며 특히 국내에서 한국인을 대상으로 한 연 구가 적은 편으로 더 활발한 연구가 요구된다. 이러한 연구 를 토대로 수면 환자의 삶의 질 향상과 수면의학 관련 산업 의 발전을 꾀할 수 있을 것이다.

\section{Conflicts of Interest}

The authors have no potential conflicts of interest to disclose.

\section{ORCID iDs}

Jiyoung Kim Jae Wook Cho https://orcid.org/0000-0002-2742-9136 https://orcid.org/0000-0001-7592-2921

\section{Author Contributions}

Conceptualization: Jae Wook Cho, Jiyoung Kim. Writing_-original draft: Jae Wook Cho, Jiyoung Kim. Writing—review \& editing: Jae Wook Cho, Jiyoung Kim.

\section{REFERENCES}

1. Wolkow A, Ferguson S, Aisbett B, Main L. Effects of work-related sleep restriction on acute physiological and psychological stress responses and their interactions: a review among emergency service personnel. Int J Occup Med Environ Health 2015;28:183-208.

2. Kecklund G, Axelsson J. Health consequences of shift work and insufficient sleep. BMJ 2016;355:i5210.

3. Hillman DR, Murphy AS, Pezzullo L. The economic cost of sleep disorders. Sleep 2006;29:299-305.

4. Colten HR, Altevogt BM; Institute of Medicine (US) Committee on Sleep Medicine and Research. Sleep disorders and sleep deprivation: an unmet public health problem. Washington: National Academies Press (US), 2006.

5. European Commission. Green Paper on mobile health ("mHealth"). 2014 Apr [cited 2018 Oct 10]. URL:https://ec.europa.eu/digital-agen$\mathrm{da} / \mathrm{en} /$ news/green-paper-mobile-health-mhealth. Access date 2018 Oct 10.

6. Stepnowsky C, Sarmiento KF, Amdur A. Weaving the internet of sleep: the future of patient-centric collaborative sleep health management using web-based platforms. Sleep 2015;38:1157-1158.

7. Zia S, Fields BG. Sleep telemedicine: an emerging field's latest frontier. Chest 2016;149:1556-1565.

8. Bruyneel M. Technical developments and clinical use of telemedicine in sleep medicine. J Clin Med 2016;5:116.

9. American Academy of Sleep Medicine. International classification of sleep disorders. 3rd ed. Darien: American Academy of Sleep Medicine, 2014.

10. Masa JF, Corral J, Pereira R, et al. Effectiveness of home respiratory polygraphy for the diagnosis of sleep apnoea and hypopnoea syndrome. Thorax 2011;66:567-573.

11. El Shayeb M, Topfer LA, Stafinski T, Pawluk L, Menon D. Diagnostic accuracy of level 3 portable sleep tests versus level 1 polysomnography for sleep-disordered breathing: a systematic review and meta-analysis. CMAJ 2014;186:E25-E51.

12. Pelletier-Fleury N, Lanoé JL, Philippe C, Gagnadoux F, Rakotonanahary D, Fleury B. Economic studies and 'technical' evaluation of telemedicine: the case of telemonitored polysomnography. Health Policy 1999;49:179-194.

13. Gagnadoux F, Pelletier-Fleury N, Philippe C, Rakotonanahary D, Fleury B. Home unattended vs hospital telemonitored polysomnography in suspected obstructive sleep apnea syndrome: a randomized crossover trial. Chest 2002;121:753-758.

14. Kristo DA, Andrada T, Eliasson AH, et al. Telemedicine in the sleep laboratory: feasibility and economic advantages of polysomnograms transferred online. Telemed J E Health 2001;7:219-224.

15. Kayyali HA, Weimer S, Frederick C, et al. Remotely attended home monitoring of sleep disorders. Telemed J E Health 2008;14:371-374.

16. Bruyneel M, Van den Broecke S, Libert W, Ninane V. Real-time attended home-polysomnography with telematic data transmission. Int J Med Inform 2013;82:696-701.

17. Pelletier-Fleury N, Gagnadoux F, Philippe C, Rakotonanahary D, Lanoé JL, Fleury B. A cost-minimization study of telemedicine. The case of telemonitored polysomnography to diagnose obstructive sleep apnea syndrome. Int J Technol Assess Health Care 2001;17:604-611.

18. Announce 2018-135. Application criteria and method for allowance of medical care-revision. The Health Insurance Review and Assessment Service 2018 Jul [cited 2018 Jul]. URL:http://www.hira.or.kr/rd/insuadtcrtr/bbsView.do?pgmid=HIRAA030069000400\&brdScnBltNo= $4 \&$ brdBltNo $=51047$. Access date 2018 Oct 10. 
19. Kribbs NB, Pack AI, Kline LR, et al. Effects of one night without nasal CPAP treatment on sleep and sleepiness in patients with obstructive sleep apnea. Am Rev Respir Dis 1993;147:1162-1168.

20. Engleman HM, Wild MR. Improving CPAP use by patients with the sleep apnoea/hypopnoea syndrome (SAHS). Sleep Med Rev 2003;7:81-99.

21. Bouloukaki I, Giannadaki K, Mermigkis C, et al. Intensive versus standard follow-up to improve continuous positive airway pressure compliance. Eur Respir J 2014;44:1262-1274.

22. Verbraecken J. Telemedicine applications in sleep disordered breathing: thinking out of the box. Sleep Med Clin 2016;11:445-459.

23. Lankford DA. Wireless CPAP patient monitoring: accuracy study. Telemed JE Health 2004;10:162-169.

24. Isetta V, León C, Torres M, et al. Telemedicine-based approach for obstructive sleep apnea management: building evidence. Interact $\mathrm{J}$ Med Res 2014;3:e6.

25. Stepnowsky CJ, Palau JJ, Marler MR, Gifford AL. Pilot randomized trial of the effect of wireless telemonitoring on compliance and treatment efficacy in obstructive sleep apnea. J Med Internet Res 2007;9:e14.

26. Hwang D, Chang JW, Benjafield AV, et al. Effect of telemedicine education and telemonitoring on continuous positive airway pressure adherence. The tele-OSA randomized trial. Am J Respir Crit Care Med 2018;197:117-126.

27. Dellacà R, Montserrat JM, Govoni L, Pedotti A, Navajas D, Farré R. Telemetric CPAP titration at home in patients with sleep apnea-hypopnea syndrome. Sleep Med 2011;12:153-157.

28. Morgenthaler TI, Aurora RN, Brown T, et al.; Standards of Practice Committee of the AASM; American Academy of Sleep Medicine. Practice parameters for the use of autotitrating continuous positive airway pressure devices for titrating pressures and treating adult patients with obstructive sleep apnea syndrome: an update for 2007. An American Academy of Sleep Medicine report. Sleep 2008;31:141-147.

29. Buysse DJ. Insomnia. JAMA 2013;309:706-716.

30. Cho YW, Shin WC, Yun CH, Hong SB, Kim J, Earley CJ. Epidemiology of insomnia in korean adults: prevalence and associated factors. J Clin Neurol 2009;5:20-23.

31. Survey on current insomnia treatment practice and influence of insomnia and sleeping pills on health in Korea. Ministry of Health and Welfare 2016 Oct [cited 2016 Oct 6]. URL:https://info.khidi.or.kr/kps/ researchInfo/list?pageNum $=9$ \&rowCnt $=10 \&$ menuId $=$ MENU02230 \& pageNum $=1 \&$ rowCnt=10\&searchContinuStYear $=\&$ searchSprcRsrhIn $\mathrm{ttNm}=\&$ searchFlnmKrn=\&search Gwrd=\&searchPjtMngmNo=\&getS earchPjtNm $=$ \&upDown $=0$. Access date 2018 Oct 10.

32. Morin CM. Cognitive-behavioral therapy of insomnia. Sleep Med Clin 2006;1:375-386

33. Edinger JD, Means MK. Cognitive-behavioral therapy for primary insomnia. Clin Psychol Rev 2005;25:539-558.

34. Ritterband LM, Thorndike FP, Gonder-Frederick LA, et al. Efficacy of an internet-based behavioral intervention for adults with insomnia. Arch Gen Psychiatry 2009;66:692-698.

35. van Straten A, Emmelkamp J, de Wit J, et al. Guided internet-delivered cognitive behavioural treatment for insomnia: a randomized trial. Psychol Med 2014;44:1521-1532.

36. Holmqvist M, Vincent N, Walsh K. Web- vs. telehealth-based delivery of cognitive behavioral therapy for insomnia: a randomized controlled trial. Sleep Med 2014;15:187-195.

37. Seyffert M, Lagisetty P, Landgraf J, et al. Internet-delivered cognitive behavioral therapy to treat insomnia: a systematic review and metaanalysis. PLoS One 2016;11:e0149139.

38. Kang SG, Kang JM, Cho SJ, et al. Cognitive behavioral therapy using a mobile application synchronizable with wearable devices for insomnia treatment: a pilot study. J Clin Sleep Med 2017;13:633-640.

39. Shambroom JR, Fábregas SE, Johnstone J. Validation of an automated wireless system to monitor sleep in healthy adults. J Sleep Res 2012; 21:221-230.

40. Perrin A. 10 facts about smartphones as the iPhone turns 10. Pew Re- search Center. 2017 June [cited 2018 Dec 2]. URL:http://www.pewresearch.org/fact-tank/2017/06/28/10-facts-about-smartphones/. Access date 2018 Nov 10.

41. Statics of wireless communications service subscriber. Ministry of Science and ICT 2018 Sep [cited 2016 Oct 6]. URL:https://msit.go.kr/web/ msipContents/contents.do?mId=MTQ2. Access date 2018 Nov 11.

42. Fox S, Duggan M. Tracking for health. Pew Research Center 2013 Jan [cited 2018 Dec 7]. URL:http://pewinternet.org/Reports/2013/Tracking-for-Health.aspx. Access date 2018 Nov 24.

43. Choi YK, Demiris G, Lin SY, et al. Smartphone applications to support sleep self-management: review and evaluation. J Clin Sleep Med 2018; 14:1783-1790.

44. Bhat S, Ferraris A, Gupta D, et al. Is there a clinical role for smartphone sleep apps? Comparison of sleep cycle detection by a smartphone application to polysomnography. J Clin Sleep Med 2015;11:709-715.

45. Toon E, Davey MJ, Hollis SL, Nixon GM, Horne RS, Biggs SN. Comparison of commercial wrist-based and smartphone accelerometers, actigraphy, and PSG in a clinical cohort of children and adolescents. J Clin Sleep Med 2016;12:343-350.

46. Patel P, Kim JY, Brooks LJ. Accuracy of a smartphone application in estimating sleep in children. Sleep Breath 2017;21:505-511.

47. Behar J, Roebuck A, Domingos JS, Gederi E, Clifford GD. A review of current sleep screening applications for smartphones. Physiol Meas 2013;34:R29-R46.

48. Sadeh A. The role and validity of actigraphy in sleep medicine: an update. Sleep Med Rev 2011;15:259-267.

49. Khosla S, Deak MC, Gault D, et al.; American Academy of Sleep Medicine Board of Directors. Consumer sleep technology: an American Academy of Sleep Medicine position statement. J Clin Sleep Med 2018; 14:877-880.

50. Examples of mobile apps For which the FDA will exercise enforcement discretion. FDA 2013 [cited 2018 Nov 20]. URL:https://www.fda. gov/MedicalDevices/DigitalHealth/MobileMedicalApplications/ ucm368744.htm. Access date 2018 Nov 20.

51. Mobile healthcare app safety management guidelines. Ministry of Food and Drug Safety. 2013 [cited 2018 Dec 7]. URL:http://www.mfds. go.kr/index.do?mid=1161. Access date 2018 Nov 20.

52. van Wouwe NC, Valk PJ, Veenstra BJ. Sleep monitoring: a comparison between three wearable instruments. Mil Med 2011;176:811-816.

53. Global fitness tracker shipment share from 2013 to 2016, by vendor. Statista 2018 Nov [cited 2018 Nov 12]. URL:https://www.statista.com/ statistics/795509/fitness-trackers-shipment-share-worldwide. Access date 2018 Nov 24.

54. Xie J, Wen D, Liang L, Jia Y, Gao L, Lei J. Evaluating the validity of current mainstream wearable devices in fitness tracking under various physical activities: comparative study. JMIR Mhealth Uhealth 2018;6:e94.

55. de Zambotti M, Goldstone A, Claudatos S, Colrain IM, Baker FC. A validation study of Fitbit Charge $2^{\mathrm{TM}}$ compared with polysomnography in adults. Chronobiol Int 2018;35:465-476.

56. Hakim M, Miller R, Hakim M, et al. Comparison of the Fitbit ${ }^{\circ}$ Charge and polysomnography for measuring sleep quality in children with sleep disordered breathing. Minerva Pediatr 2018 Nov 7 [Epub ahead of print]. https://doi.org/10.23736/S0026-4946.18.05333-1.

57. From wearables to invisibles. Emerald 2018 Apr [cited 2018 Nov 25]. URL:https://www.emeraldinno.com. Access date 2018 Nov 25.

58. Hsu CY, Ahuja A, Yue S, Hristov R, Kabelac Z, Katabi D. Zero-effort in-home sleep and insomnia monitoring using radio signals. Proceedings of the ACM on Interactive, Mobile, Wearable and Ubiquitous Technologies 2017;1:59.

59. Zhao M, Yue S, Katabi D, Jaakkola TS, Bianchi MT. Learning sleep stages from radio signals: a conditional adversarial architecture. Proceedings of the 34th International Conference on Machine Learning;2017 August 6-11;Sydney, Australia.

60. Sleep Bot. 2016 Apr [cited 2018 Nov 24]. URL:http://mysleepbot.com/. Access date 2018 Nov 24. 
61. Chawla NV, Davis DA. Bringing big data to personalized healthcare: a patient-centered framework. J Gen Intern Med 2013;28 Suppl 3:S660S665.

62. Zhang Y, Zhu Q, Liu H. Next generation informatics for big data in precision medicine era. BioData Min 2015;8:34.

63. Budhiraja R, Thomas R, Kim M, Redline S. The role of big data in the management of sleep-disordered breathing. Sleep Med Clin 2016;11: 241-255.

64. Bianchi MT, Russo K, Gabbidon H, Smith T, Goparaju B, Westover MB. Big data in sleep medicine: prospects and pitfalls in phenotyping. Nat Sci Sleep 2017;9:11-29.

65. Dean DA 2nd, Goldberger AL, Mueller R, et al. Scaling up scientific discovery in sleep medicine: the National Sleep Research Resource. Sleep 2016;39:1151-1164.

66. O’Reilly C, Gosselin N, Carrier J, Nielsen T. Montreal Archive of Sleep Studies: an open-access resource for instrument benchmarking and exploratory research. J Sleep Res 2014;23:628-635.
67. National Health Insurance Sharing Service 2018 Nov [cited 2018 Nov 26]. URL:https://nhiss.nhis.or.kr/bd/ay/bdaya001iv.do. Access date 2018 Nov 26.

68. Healthcare Bigdata Hub. 2015 [cited 2018 Nov 26]. URL:http://opendata.hira.or.kr/home.do\#none. Access date 2018 Nov 26.

69. Investigating the prevalence and characteristics of sleep disorder and co-morbidity using the Korean Nation Health Insurance Service. National Health Insurance Service Ilsan Hospital 2015 [cited 2018 Dec]. file://C:/Users/admin/Downloads/audit05_etc32\%20(1).pdf.

70. KoGES. KCDC 2014 Apr [cited 2018 Nov 18]. URL:http://www.cdc. go.kr/CDC/contents $/$ CdcKrContentView.jsp?cid=24606\&viewType $=$ CDC\&menuIds=HOME001-MNU1136-MNU2530-MNU1223MNU1348. Access date 2018 Nov 18.

71. Kwon AM, Shin C. Structural equation modelling for the effect of physical exercise on excessive daytime sleepiness. Public Health 2016;141:95-99.

72. Schwab, K. The fourth industrial revolution. New York: Crown Publishing Group, 2017. 